\title{
Effects of host plant species on the development of Dysdercus cingulatus (Heteroptera: Pyrrhocoridae)
}

\author{
Katsuyuki KoHNO* and BuI Thi Ngan \\ Okinawa Subtropical Station, Japan International Research Center for Agricultural Sciences; Maezato, Ishigaki, Okinawa \\ 907-0002, Japan
}

(Received 7 May 2003; Accepted 11 November 2003)

\begin{abstract}
The survivability and the developmental rates of Dysdercus cingulatus when fed various cultivated and wild host plant species were compared in the laboratory. On this basis, Chorisia speciosa was regarded as a better-than-adequate host plant for D. cingulatus. Abelmoschus moschatus, A. esculentus, Hibiscus makinoi, Thespesia populnea and Gossypium arboreum were adequate, $H$. tiliaceus was relatively poor, and Abutilon indicum was very poor. Although D. cingulatus developed faster when fed cultivated species than when fed wild species, host plant properties such as the weight of seeds and habit (arboreal or herbaceous) could not explain the survivability and developmental rate of D. cingulatus when fed the different species. Estimations of a lower threshold temperature for the development of $D$. cingulatus nymphs fed with plant species except for $A$. indicum fell within a range of 0.5 degrees $\left(13.9\right.$ to $\left.14.4^{\circ} \mathrm{C}\right)$. However, the estimated total effective temperature for development varied so widely among food plant species that its value for $A$. indicum was more than twice that for Ch. speciosa. Developmental parameters obtained here may be applied to the design of control programs for $D$. cingulatus in cotton fields adjacent to or near vegetative stands containing alternative wild host plants.
\end{abstract}

Key words: Dysdercus cingulatus; Malvaceae; Bombacaceae; development; alternative host plant

\section{INTRODUCTION}

Cotton is the most economically important natural fiber material in the world. One of the major obstacles hindering cotton cultivation is insect pest infestations. In particular, the cotton stainers Dysdercus spp. (Heteroptera: Pyrrhocoridae) cause serious damage by feeding on developing cotton balls and ripe cotton seeds and transmitting fungi that develop on the immature lint and seeds (Maxwell-Lefroy, 1908; Freeman, 1947; Van Doesburg, 1968; Fuseini and Kumar, 1975; Iwata, 1975, 1978a; Ahmad and Kahn, 1980; Ahmad and Schaefer, 1987; Yasuda, 1992). These pests are difficult to control by insecticide application because they are highly mobile and have many alternative wild host plants (Iwata, 1975, 1978a, b). For the control of these pests in cotton fields it is therefore critical to elucidate their life cycle on alternative wild host plants.

Among various Dysdercus species, D. cingulatus (Fabricius) is the most serious pest species of cot- ton and okra plants in Southeast Asia, and is also common on Ishigaki-jima Island, the southernmost of the Southwest Islands of Japan. There exist two subspecies of $D$. cingulatus in the world; $D$. cingulatus cingulatus (Fabricius), occurring in Southeast Asia, the Oriental Region and Australia, and D. cingulatus nigriventris Stehlík, 1965, endemic to the Solomon Islands (Ysabel Island) (Kerzhner, 2001). All the materials treated and discussed in this study belong to ssp. cingulatus. The following plant species are known to be host plant species of D. cingulatus on Ishigaki-jima Island (Kohno, 2001; Kohno, unpublished): Abelmoschus moschatus Medik., the okra plant A. esculentus Moench, Hibiscus tiliaceus L., H. rosa-sinensis L., H. syriacus L., H. mutabilis L., H. makinoi Jotani et Ohba, the kenaf plant $H$. cannabinus L., Thespesia populnea (L.), Abutilon indicum (L.), Malvastrum coromandelianum (L.) and the cotton plant Gossypium arboreum L.- all of which belong to the Malvaceae family-and Chorisia speciosa St. Hil. and Bombax ceiba L. of the Bombacaceae family.

\footnotetext{
* To whom correspondence should be addressed at: E-mail: kohno@affrc.go.jp
} 
Among these host plants, okra is herbaceous and commercially cultivated, kenaf and cotton are also herbaceous and experimentally cultivated, and $H$. rosa-sinensis, H. syriacus, H. mutabilis, Ch. speciosa and $B$. ceiba are exotic arboreals ornamentally cultivated on the island. H. tiliaceus and Th. populnea are common arboreal species of the island's maritime forest and are in some instances cultivated ornamentally on the island. H. makinoi is a common arboreal species in and around the forest near the island mountains. A. moschatus, A. indicum and $M$. coromandelianum are common herbaceous species prevailing in the open lands of the island.

The overall purpose of this study was to elucidate the relationship between life history traits of D. cingulatus, the most serious cotton pest species among Asian Dysdercus, and its host plant species. We compared the survivability and the developmental rate of this species when fed the abovementioned Malvales species in the laboratory. We also determined the developmental rates when reared with the various wild host plant species under various temperatures. This latter data may be especially useful in Southeast Asian cotton-producing countries for predicting the occurrence of $D$. cingulatus in cotton fields adjacent to or near vegetative stands containing these wild host plant species.

\section{MATERIALS AND METHODS}

Seeds of Abelmoschus moschatus, A. esculentus, Hibiscus tiliaceus, H. makinoi, Thespesia populnea, Abutilon indicum, Gossypium arboreum (Malvaceae) and Chorisia speciosa (Bombacaeae) collected on Ishigaki-jima Island were provided for the experiment as diet for $D$. cingulatus. All the plant species listed above are commonly used as host plant by $D$. cingulatus on Ishigaki-jima Island. Among the above listed species, A. moschatus, $H$. tiliaceus, Th. populnea and A. indicum are wild and widely distributed in tropical and subtropical Asia (Hatusima, 1975) and overlap with cotton cultivation areas to a considerable extent. The seed weights of the above-mentioned plant species were measured for 10 seeds to analyze the relationship between the seed weight and adequacy as a diet for D. cingulatus. The seed weights are substituted for seed size in the discussion.
Eggs of $D$. cingulatus for the experiments were obtained from females collected from fields on Ishigaki-jima Island and kept at room temperature (ca. $25^{\circ} \mathrm{C}$ ) under natural photoperiods until oviposition. Within $24 \mathrm{~h}$ after oviposition the eggs were moved to conditions of 20.0,22.5, 25.0, 27.5, or $30.0^{\circ} \mathrm{C}$ and $14 \mathrm{~L}-10 \mathrm{D}$ photoperiod and kept in a plastic container (ca. $5 \mathrm{~cm}$ in diameter and $1 \mathrm{~cm}$ in depth) with moistened filter paper until molting to the second stadium nymphs. After that each nymph was kept singly in a plastic container and provided with water and one species of host plant seeds ad libitum. Nymphs were examined every day until adult emergence and the duration of each developmental stadium was calculated. Thirty-six hatchlings were examined for each temperature and food treatment.

\section{RESULTS}

The seed weights of all host plant species tested are shown in Table 1. The seeds of Th. populnea were the heaviest, more than seventy times the weight of the smallest seeds of $H$. makinoi and $A$. indicum. Cultivated species (A. esculentus, G. arboreum and Ch. speciosa) generally exhibited greater seed weights than wild species. However, the difference was not significant ( $p>0.1$ by MannWhitney's $U$ ). The difference in seed weight between arboreal species and herbaceous species examined was not significant ( $p>0.2$ by Mann-Whitney's $U$ ).

Survivability during total nymphal stadia of $D$. cingulatus when fed seeds of eight plant species (Fig. 1) differed significantly among the eight food species provided $\left(p<0.001\right.$ by Pearson's $\left.\chi^{2}\right)$, but not among the five rearing temperature regimes $\left(p>0.05\right.$ by Pearson's $\chi^{2}$ ). The survivability of $D$. cingulatus was very low when fed $A$. indicum, low when fed $H$. tiliaceus, and intermediate when fed A. moschatus. All the cultivated host plants exhibited relatively high survivability for $D$. cingulatus. The survivability of $D$. cingulatus when fed $H$. makinoi and Th. populnea (both wild species) was also high. However, differences in nymphal survivability could not be explained by the weight of host plant seeds ( $p>0.05$ by Kendall's $\tau$ ), the status of host plant as wild or cultivated ( $p>0.1$ by MannWhitney's $U$ ), or the plant habit, whether arboreal or herbaceous ( $p>0.1$ by Mann-Whitney's $U$ ). 
Table 1. Weight of host plant seeds examined

\begin{tabular}{lclc}
\hline \multicolumn{1}{c}{ Plant species } & Weight/seed (mg) & \multicolumn{1}{c}{ Wild/cultivated } & Arboreal/herbaceous \\
\hline Malvaceae & & & herbaceous \\
Abelmoschus moschatus & 10.6 & wild in openland & herbaceous \\
A. esculentus & 48.7 & cultivated commercially & arboreal \\
Hibiscus tiliaceus & 10.7 & wild in maritime beach forest & arboreal \\
H. makinoi & 3.5 & wild in and around forest near mountains & arboreal \\
Thespesia populnea & 256.4 & wild in maritime beach forest & herbaceous \\
Abutilon indicum & 3.5 & wild in openland & herbaceous \\
Gossypium arboreum & 56.1 & cultivated experimentally & arboreal \\
Bombacaceae & 88.7 & cultivated ornamentally & \\
Chorisia speciosa & & &
\end{tabular}

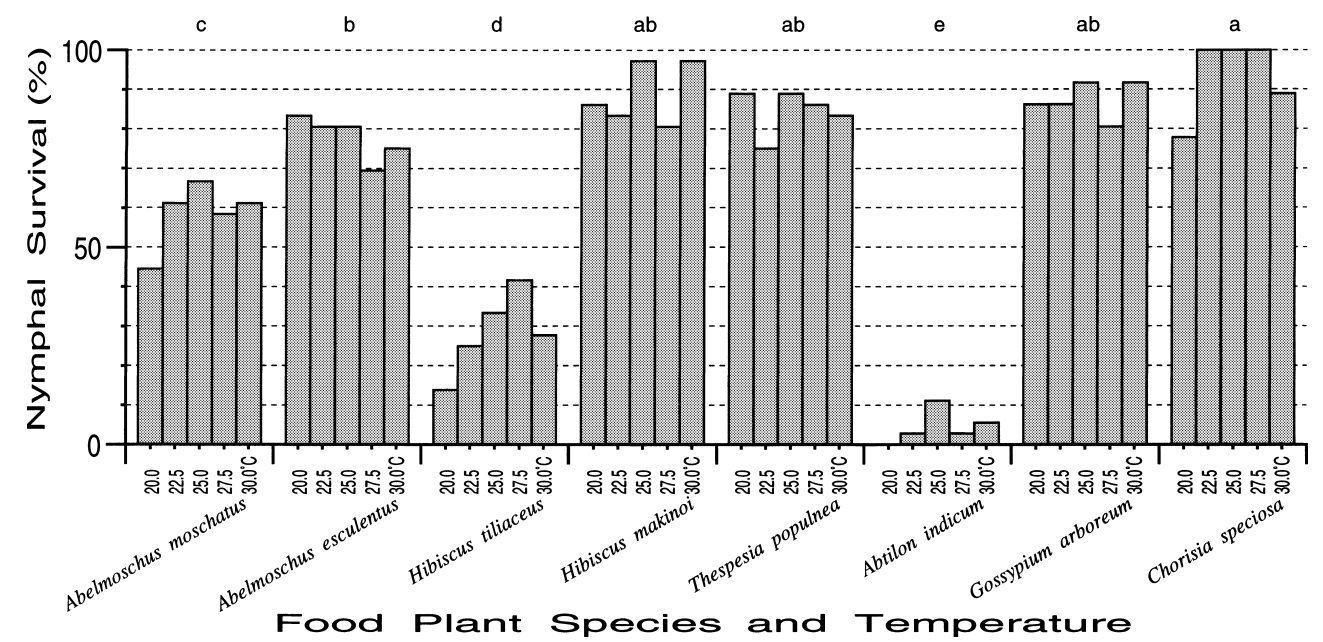

Fig. 1. Survivability during total nymphal stadia of $D$. cingulatus under five temperature regimes between 20.0 and $30.0^{\circ} \mathrm{C}$ and a 14L-10D photoperiod when fed seeds of eight plant species. Identical letters above columns indicate the values of survivability are not significantly different ( $p>0.05$; Tukey's method).

Total nymphal developmental periods of $D$. cingulatus when fed seeds of eight plant species (Fig. 2) differed significantly among the eight food species provided $(p<0.001$ by ANOVA) for all rearing temperatures. In the rearing temperature regime of $25^{\circ} \mathrm{C}$, the developmental period was very long when fed A. indicum, long when fed H. tiliaceus, short when fed Ch. speciosa, and intermediate when fed the other five species examined. The nymphal developmental period when fed wild host plant seeds was significantly longer than when fed cultivated host plant seeds $\left(25^{\circ} \mathrm{C} ; p<0.001\right.$ by $t$ test). However, neither the weight of host plant seeds ( $p>0.1$ by Kendall's $\tau$ ) nor the habit of the host plant $(p>0.1$ by Mann-Whitney's $U$ ) explained differences in the nymphal developmental period $\left(25^{\circ} \mathrm{C}\right)$.

Relatively good regressions were obtained be- tween the developmental rate for nymphs and rearing temperatures for all food plant species (Table 2 ). The estimated lower threshold temperatures for development of nymphs varied from 13.3 to $14.4^{\circ} \mathrm{C}$, and did not differ much among food plant species. However, estimated total effective temperature for the development of nymphs differed greatly among food plant species. The value for a diet of $A$. indicum was more than twice that for a diet of Ch. speciosa. The developmental rate for eggs also exhibited good regression to the rearing temperatures, $\quad v=-0.214686+0.0136285 t \quad\left(r^{2}=\right.$ $0.98)$. The lower threshold temperature for development and the total effective temperature of eggs were estimated to be $15.8^{\circ} \mathrm{C}$ and 73.4 day-degrees, respectively. The lower threshold temperature for development of eggs was apparently higher than for nymphs. 


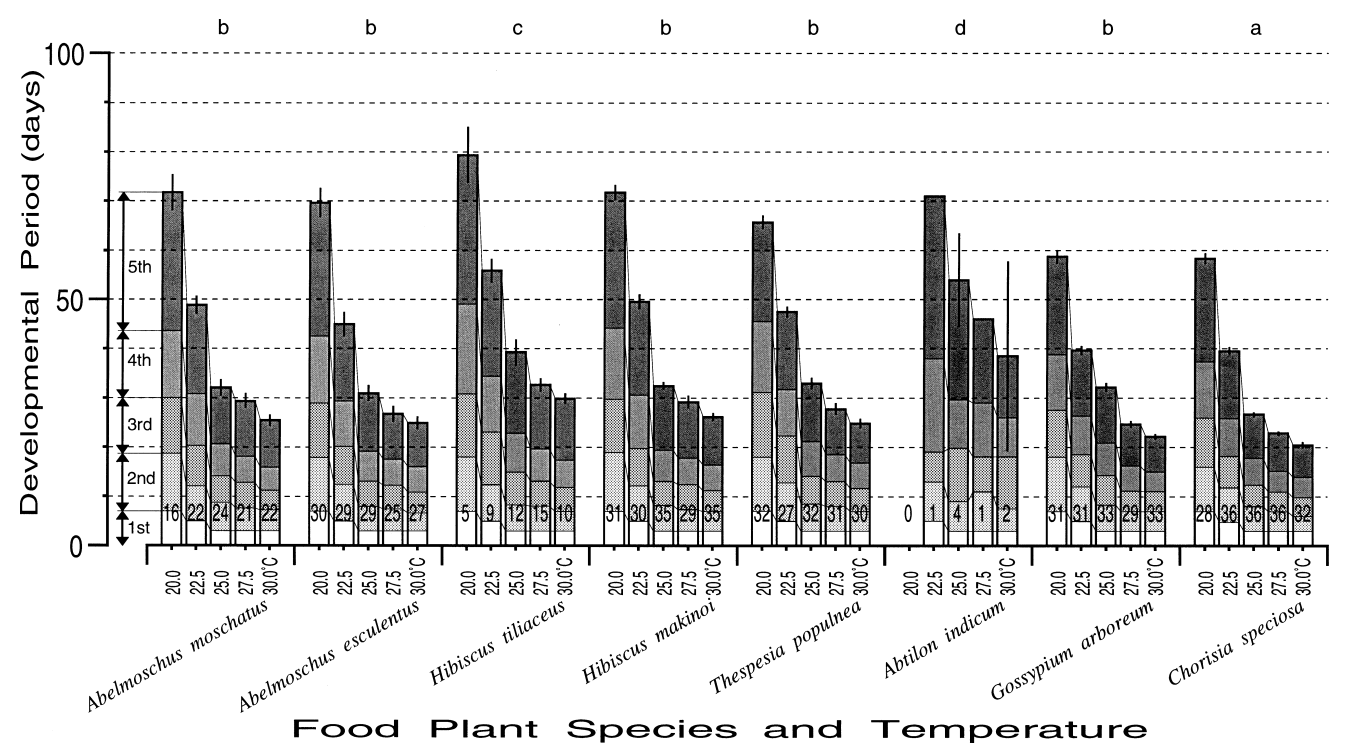

Fig. 2. Nymphal developmental periods of successfully emergent Dysdercus cingulatus under five temperature regimes between 20.0 and $30.0^{\circ} \mathrm{C}$ and a $14 \mathrm{~L}-10 \mathrm{D}$ photoperiod when fed seeds of eight plant species. Vertical columns indicate mean developmental periods of each nymphal stadium, and bars indicate $95 \%$ confidence intervals of means of total nymphal developmental periods. The number in each column is the number of successfully emergent insects. Identical letters above columns indicate the values for the total nymphal developmental period at $25^{\circ} \mathrm{C}$ are not significantly different ( $p>0.05$; Tukey-Kramer's HSD).

Table 2. Thermal requirements for nymphal development of Dysdercus cingulatus estimated from data for $20,22.5,25,27.5$ and $30^{\circ} \mathrm{C}$ and $14 \mathrm{~L}-10 \mathrm{D}$ when fed seeds of eight plant species

\begin{tabular}{|c|c|c|c|c|}
\hline Food species & Regression equation & $r^{2}$ & $\begin{array}{l}\text { Lower threshold } \\
\text { temperature }\left({ }^{\circ} \mathrm{C}\right)\end{array}$ & $\begin{array}{c}\text { Total effective } \\
\text { temperature } \\
\text { (day-degrees) }\end{array}$ \\
\hline Abelmoschus moschatus & $v=-0.03632+0.002563 t$ & 0.964 & 14.2 & 390.2 \\
\hline A. esculentus & $v=-0.03730+0.002661 t$ & 0.957 & 14.0 & 375.8 \\
\hline Hibiscus tiliaceus & $v=-0.03037+0.002174 t$ & 0.979 & 14.0 & 459.9 \\
\hline H. makinoi & $v=-0.03507+0.002501 t$ & 0.959 & 14.0 & 399.8 \\
\hline Thespesia populnea & $v=-0.03628+0.002593 t$ & 0.984 & 14.0 & 385.6 \\
\hline Abutilon indicum ${ }^{\mathrm{a}}$ & $v=-0.02076+0.001556 t$ & 0.997 & 13.3 & 642.8 \\
\hline Gossypium arboreum & $v=-0.03950+0.002850 t$ & 0.991 & 13.9 & 350.8 \\
\hline Chorisia speciosa & $v=-0.04704+0.003260 t$ & 0.976 & 14.4 & 306.7 \\
\hline
\end{tabular}

\footnotetext{
${ }^{\text {a }}$ From data for $22.5,25,27.5$ and $30^{\circ} \mathrm{C}$.
}

The plant species that exhibited higher survivability also exhibits faster development, and vice versa ( $p<0.05$ by Kendall's $\tau$ between the survivability and the total effective temperature). This implies that survivability and developmental rate of D. cingulatus nymphs can be used as a measure of adequacy for the development of $D$. cingulatus. On this basis, Ch. speciosa was judged to be a betterthan-adequate host plant for D. cingulatus. A. moschatus, A. esculentus, H. makinoi, Th. populnea and $G$. arboreum were adequate, H. tiliaceus was relatively poor, and $A$. indicum was very poor.

\section{DISCUSSION}

Among the wild plant species examined, $A$. moschatus, $H$. makinoi and Th. populnea are judged to be adequate host plants for $D$. cingulatus. Although H. makinoi is endemic to the Southwest Islands of Japan including Ishigaki-jima Island (Jotani and Ohba, 1984), A. moschatus and Th. populnea are widely distributed in Southeast Asian countries (Hatusima, 1975). Since the distribution of $D$. cingulatus overlaps with these two Southeast Asian wild Malvales which are adequate food for 
D. cingulatus, it is possible that these two Malvales are primitive host plant species of $D$. cingulatus.

The estimated lower threshold temperature for the nymphal development of $D$. cingulatus did not differ greatly with different diets (Table 2). If the estimate when fed $A$. indicum is excluded from consideration (based on very scarce data), all the estimates fell within the range of 0.5 degrees (13.9 to $14.4^{\circ} \mathrm{C}$ ). It can be concluded that differences in diet affect only the developmental rate above the lower threshold temperature. The lower threshold temperature of $D$. cingulatus is relatively high among heteropterous insects inhabiting Japan (Kiritani, 1997). This can be one of the limiting factors determining the northern limit of distribution of D. cingulatus at Okinoerabu-jima Island (Hayashi, 2002), since adequate wild host plants, H. makinoi, are distributed in the more northern areas (Jotani and Ohba, 1984). However, the photoperiodic reaction of $D$. cingulatus and the phenology of $H$. makinoi need to also be considered.

Among the wild plant species examined in this study, A. moschatus, H. tiliaceus, Th. populnea and A. indicum are widely distributed in tropical and subtropical Asia (Hatusima, 1975) and overlap cotton cultivation areas to a considerable extent. Developmental parameters obtained in this study may be applied to the design of control programs for $D$. cingulatus in cotton fields adjacent to or near vegetative stands containing these alternative wild host plants by monitoring or controlling $D$. cingulatus populations on the wild alternative host plants. The phenology of these alternative host plants in cotton cultivation areas should also be considered, as $D$. cingulatus is principally a seed feeder (Van Doesburg, 1968; Ahmad and Schaefer, 1987).

\section{ACKNOWLEDGEMENTS}

We thank two anonymous reviewers for valuable comments on earlier drafts of this paper.

\section{REFERENCES}

Ahmad, I. and N. H. Kahn (1980) Effects of starvation on the longevity and fecundity of red cotton bug, Dysdercus cingulatus (Hemiptera: Pyrrhocoridae) in successive selected generations. Appl. Entomol. Zool. 15: 182-183.
Ahmad, I. and C. W. Schaefer (1987) Food plant and feeding biology of the Pyrrhocoroidea (Hemiptera). Phytophaga 1: 75-92.

Freeman, P. (1947) A revision of the genus Dysdercus Boisduval (Hemiptera, Pyrrhocoridae), excluding the American species. Trans. Royal Entomol. Soc. London 98: 373-424.

Fuseini, B. A. and R. Kumar (1975) Ecology of cotton stainers (Heteroptera: Pyrrhocoridae) in southern Ghana. Biol. J. Linn. Soc. 7: 113-146.

Hatusima, S. (1975) Flora of the Ryukyus (including Amami Islands, Okinawa Islands, and Sakishima Archipelago) (Added and Corrected). Okinawa Seibutsu Kyoiku Kenkyu-kai, Naha. 1,022 pp. (in Japanese).

Hayashi, M. (2002) Heteroptera. In Check List of the Insect of the Ryukyu Islands (S. Azuma ed.). The Biological Society of Okinawa, Naha. 570 pp. (in Japanese).

Iwata, K. (1975) Shizen kansatsusha no shuki (Memoirs on Nature by an Observer). Asahi Shimbun Co., Tokyo. 584 pp. (in Japanese).

Iwata, K. (1978a) Konchu wo mitsumete 50 nen (Fifty-YearObservation of Insects). Volume 1. Asahi Shimbun Co., Tokyo. 343 pp. (in Japanese).

Iwata, K. (1978b) Konchu wo mitsumete 50 nen (Fifty-YearObservation of Insects). Volume 2. Asahi Shimbun Co., Tokyo. 330 pp. (in Japanese).

Jotani, Y. and H. Ohba (1984) A wild Hibiscus, H. Makinoi, sp. nov. from S. W. Japan. J. Jap. Bot. 59 (7): 22-30 (in Japanese with English summary).

Kerzhner, I. M. (2001) Family Pyrrhocoridae Amyot \& Serville, 1943. In Catalogue of the Heteroptera of the Palaearctic Region (B. Aukema and C. Rieger eds.). Netherlands Entomological Society, Amsterdam, pp. 248-258.

Kiritani, K. (1997) The lower development threshold temperature and the thermal constant in insects, mites and nematodes in Japan. Misc. Publ. Natl. Inst. Agro-Environ. Sci. No. 21: 1-72 (in Japanese with English summary).

Kohno, K. (2001) Host plant of Dysdercus poecilus (Heteroptera: Pyrrhocoridae) and its relative species in Ishigaki-jima Island, the Ryukyus, Japan. Rostria 50: 31-34 (in Japanese with English summary).

Maxwell-Lefroy, H. (1908) The red cotton bug (Dysdercus cingulatus Fabr.). Mem. Dept. Agric. India (Entomol. Ser.) 2: 47-58.

Van Doesburg, P. H. Jr. (1968) A revision of the new world species of Dysdercus Guérin Méneville (Heteroptera, Pyrrhocoridae). Zool. Verh. 97: 1-215.

Yasuda, K. (1992) Cotton bug. In Insect Pests of Vegetables in the Tropics (T. Hidaka ed.). Association for International Cooperation of Agriculture and Forestry, Tokyo, pp. 22-23 (in Japanese). 